
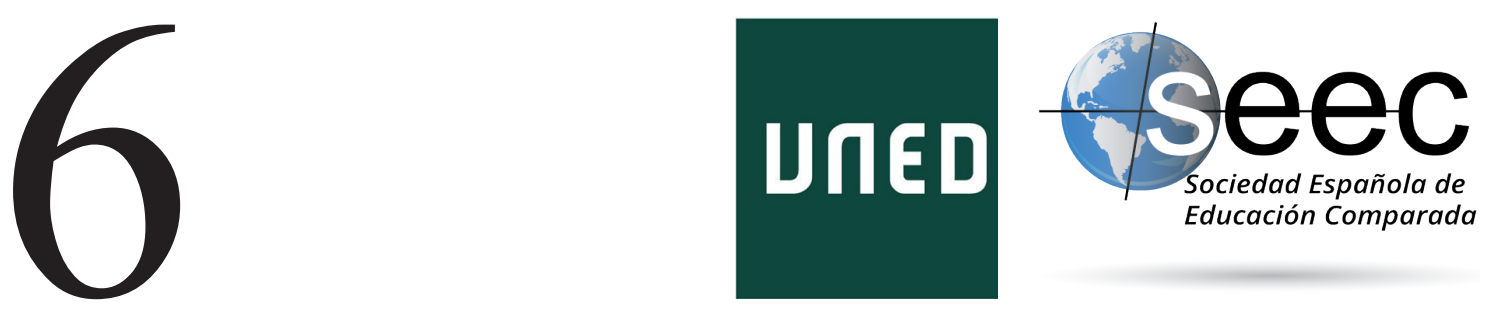

\title{
Gestión educativa del confinamiento por COVID-19: percepción del docente en España
}

\author{
Educational management of confinement by \\ COVID-19: teacher perception in Spain
}

\section{José Hernández-Ortega*; Juan-Francisco Álvarez-Herrero**}

DoI: $10.5944 /$ reec.38.2021.29017

\section{Recibido: 1 de diciembre de 2020 Aceptado: $\mathbf{2 8}$ de enero de $\mathbf{2 0 2 1}$}

\footnotetext{
* José Hernández-Ortega: Doctor en Ciencias de la Educación. Profesor asociado en la Universidad Internacional de Valencia en la Facultad de Educación. Sus líneas de investigación se centran en el aprendizaje mediado por tecnología, las narrativas transmedia, las metodologías activas y la formación del profesorado en entornos digitales. Miembro del grupo de investigación consolidado DETECESE (Desarrollo tecnológico, exclusión sociocultural y educación) de la Universidad Complutense de Madrid. Datos de contacto: E-mail: josehernandezortega@ucm.es. ORcID: https://orcid.org/oooo-0oo3-3556-5688

** Juan-Francisco Állvarez-Herrero: Profesor Ayudante-Doctor en el Departamento de Didáctica General y Didácticas Específicas de la Facultad de Educación. Universidad de Alicante. Entre sus numerosos trabajos, destacan: Álvarez-Herrero, J. F. \& Gisbert, M. (2015), Grado de alfabetización informacional del profesorado de Secundaria en España: Creencias y autopercepciones, Comunicar, 45; (2020), El poder de la anticipación en la evaluación: simulacros de examen y rúbricas en la educación superior, Aloma, 38(2). Datos de contacto: E-mail: juanfran.alvarez@ua.es. ORCID: http://orcid.org/oooo-ooo2-9988-8286
} 


\title{
Resumen
}

El confinamiento domiciliario ocasionado por la pandemia por COVID-19 ha supuesto el mayor reto de adaptación y transformación del sistema educativo español registrado hasta la fecha. El cambio del paradigma educativo, con especial atención al cambio de ubicación, metodología, medios y evaluación, ha puesto de manifiesto que el proceso no ha sido satisfactorio para todos los agentes implicados. El presente estudio muestra la perspectiva de un grueso de 3764 docentes de todos los niveles educativos que ejercen su labor docente en centros representados de todas las comunidades autónomas. En el cuestionario se aborda la perspectiva de estos docentes en relación a una serie de cuestiones que pretenden corroborar la existencia de una brecha multidimensional (metodología, socio-económica y tecnológica) además de comprobar la eficacia de la gestión educativa. La opinión de los docentes tanto de la propia labor realizada como la llevada a cabo por las administraciones educativas y las familias, arroja resultados heterogéneos a partir de variables de niveles educativos, demarcación geográfica o medios disponibles. Asimismo, la opinión del profesorado hacia las familias es satisfactoria, equiparable a la propia acción. En cambio, la valoración que reciben los planes de formación en competencias digitales y la respuesta de la administración educativa para afrontar una transformación del sistema educativo no satisfacen al conjunto del profesorado. El artículo muestra que la brecha digital no es tan sólo instrumental, sino de adaptación de un sistema educativo que, pese a tener planificado un plan de digitalización, no se ha llevado a cabo con la prioridad y consistencia como así ha demostrado uno de los agentes educativos implicados directamente en este proceso, el profesorado..

Palabras clave: Educación; Política educativa; Gestión de centro de enseñanza; Tecnología de la educación.

\begin{abstract}
The home confinement caused by the COVID-19 pandemic has represented the greatest challenge of adaptation and transformation of the Spanish educational system registered to date. The change in the educational paradigm, with special attention to the change of location, methodology, means and evaluation, has shown that the process has not been satisfactory for all the agents involved. This study shows the perspective of a bulk of 3764 teachers of all educational levels who carry out their teaching work in centers represented from all the autonomous communities. The questionnaire addresses the perspective of these teachers in relation to a series of questions that seek to corroborate the existence of a multidimensional gap (methodology, socio-economic and technological) in addition to verifying the effectiveness of educational management. Teachers' opinion of both their own work and that carried out by educational administrations and families, yields heterogeneous results based on variables of educational levels, geographic demarcation or available means. Likewise, the opinion of the teaching staff towards the families is satisfactory, comparable to the action itself. On the other hand, the evaluation received by the training plans in digital skills and the response of the educational administration to face a transformation of the educational system do not satisfy all the teachers. The article shows that the digital divide is not only instrumental, but also an adaptation of an educational system that, despite having a digitization plan planned, has not been carried out with the priority and consistency as demonstrated by one of the agents educators directly involved in this process, the teaching staff.
\end{abstract}

Keywords: Education; Educational policy; School management; Educational Technology. 


\section{Introducción}

Los efectos derivados de la irrupción de la COVID-19 trascienden el ámbito sanitario. Desde el punto de vista económico, social y educativo, se han concatenado una serie de efectos colaterales que han hecho florecer la fragilidad de un sistema educativo y socioeconómico ante circunstancias complejas y sobrevenidas. El confinamiento obligatorio ha afectado directamente a la garantía del derecho a la educación, derecho fundamental recogido por los Objetivos de Desarrollo Sostenible de la Organización para las Naciones Unidas (ONU, 2019). Las múltiples vicisitudes que la COVID-19 ha generado en el sistema educativo global, pero en el español en particular, han sido analizadas y tipificadas por la UNESCO (2020). El impacto en centros educativos españoles, estudiantes, docentes y familias va más allá del cambio de ubicación natural (el aula) afectando directamente de distintas formas, como así arrojan las recientes investigaciones sobre los impactos del confinamiento (Moreno et al., 2020; Trujillo et al., 2020; Azorín, 2020; Aznar Sala, 2020; Gromova, 2020; Teräs et al., 2020) que arrojan una situación educativa heterogénea:

- Interrupción de los procesos de aprendizaje. El confinamiento genera desigualdades en las oportunidades de aprendizaje y desarrollo para el alumnado que sí se ofrecen en la asistencia a la escuela.

- Carencias del profesorado en la conversión digital. La transición a las plataformas digitales de aprendizaje no ha sido natural y ha arrojado la ausencia de planes de formación y de adaptación curricular al entorno digital.

- Familias sin competencia ni recursos digitales. El confinamiento ha mostrado la situación heterogénea en el acceso, conocimiento y gestión del entorno digital por parte las familias.

- Conversión digital improvisada. La transición del aula a los hogares supone un reto en el que las administraciones gubernamentales, escolares y humanas han de sobreponerse a las limitaciones humanas y técnicas que han quedado patentes.

- Incremento en las brechas económicas, humanas y afectivas entre alumnado, familias y centros educativos. El contexto tan singular ha generado que las escuelas y los sistemas educativos reciban una presión no conocida hasta el momento.

- El desconocimiento de la pedagogía de la evaluación a distancia, interrupción de evaluaciones y del seguimiento del alumnado en contextos de confinamiento, generan contextos de inseguridad tanto en equipos docentes como en las familias y el alumnado.

Cambiar el modelo y contexto educativo, en una transición súbita y marcada por una pandemia global es un hecho que no debería ser improvisado a fin de dotar a la totalidad del alumnado del derecho a la Educación (Gromova, 2020). En un tiempo récord, la comunidad educativa transformó la docencia presencial analógica por un modelo digital que no estaba consolidado ni en su currículum ni en los medios para llevarlo a cabo. Una situación 
en la que se requirió de grandes dosis de adaptación, creatividad y supervivencia a un ecosistema al que muchos docentes y familias todavía no habían ingresado bien por falta de medios, formación y/o actitud hacia la tecnología educativa (la Velle, 2020; Tejedor et al., 2020). Por este motivo se desarrolla la presente investigación, llevada a cabo durante el mes de mayo de 2020, en la que se analiza e interpreta una primera realidad en boca del profesorado como de las familias que han vivido esta pandemia. Este informe se centra en la perspectiva docente, por ser el eje de unión entre el alumnado y la escuela.

La principal hipótesis que aborda el presente trabajo es la existencia de una brecha sociocultural en la sociedad española que se traslada inexorablemente al contexto escolar. La crisis COVID-19 amenaza con incrementar esta brecha, pudiendo hacerla irreversible en los entornos y usuarios más desfavorecidos. El cierre de las escuelas es el cierre de un modelo social y cultural que cumple una función formativa, privando de igualdad y excluyendo a sectores esenciales en la población (Burgess \& Sievertsen, 2020; Moya \& Hernández-Ortega, 2020) . Esta brecha en el aprendizaje se relaciona directamente con el modelo curricular, que urge de una reforma estructural hacia un modelo competencial e integrador.

No menos importante es la consolidación de la brecha digital que afecta tanto a las instituciones educativas como a alumnado y profesorado. El acceso a la tecnología es muy heterogéneo y, pese a tener posibilidad de acceso, el uso y gestión de la misma es deficitario en gran parte de la población (Fernández-Regueira et al., 2020; Cabero-Almenara \& Llorente-Cejudo, 2020; García-Peñalvo \& Corell, 2020; Area-Moreira et al., 2020). El acceso a la tecnología en el contexto educativo se ha fomentado desde comienzos de siglo, si bien, no ha tenido una incorporación proporcional. Desde su pragmática, el acceso a la tecnología educativa se debe al uso y desarrollo de las competencias digitales inherentes a su puesta en funcionamiento:

"Once schools were wired and equipment was in place, policymakers assumed, teachers and students would use the information technologies regularly in classrooms, and once computers were used regularly in schools, the desired outcomes, divergent as they were, would naturally follow. In short, access to technology would lead to instructional use, and use would lead to achievement of the goals" (Cuban, 2004, p. 20-21)

Una puesta en marcha que todavía se encuentra en fase de implementación a rasgos generales y que, por el contrario, ha incentivado involuntariamente la consolidación de una brecha entre los distintos agentes que se materializa en dos frentes claramente diferenciados:

a) Familias y alumnado. El uso de las TIC está condicionado por la competencia digital de la que disponen las familias para brindar el apoyo al alumnado para la formación de sus domicilios.

b) Docentes e instituciones educativas. Los recursos económicos de los centros educativos, junto con la gestión de la formación del profesorado, ponen de manifiesto la necesidad de tres modelos de aprendizaje, condicionados por la evolución de la pandemia: modelo presencial, modelo a distancia y modelo híbrido.

Es a partir de la brecha digital que, cuando la tecnología debería ser una herramienta para la minimización del cierre de los centros educativos, se incrementen las 
desigualdades de forma paradójica. Desigualdades que ya existían antes de esta crisis sanitaria pero que, derivada de su irrupción, se han potenciado y requieren de actuaciones mitigadoras que aborden su solución (Moreno et al, 2020; Trujillo et al., 2020, Aznar Sala, 2020). Como objetivo prioritario de nuestra investigación nos propusimos conocer cuál había sido la valoración que sobre la gestión educativa del confinamiento de la COVID-19 tenía el profesorado del estado español.

\section{Método}

Para llevar a cabo este estudio se ha empleado un método mixto, del que ofrecemos los datos cuantitativos por considerarlos los más adecuados al propósito del presente artículo. Esta metodología es relevante para Teddlie y Tashakkori (2003) relevantes puesto que ofrecen el eclecticismo metodológico así como el pluralismo paradigmático. Desde el punto de vista ecléctico, es un método que conlleva la selección, uso e integración de los procesos metodológicos más apropiados entre los enfoques cualitativos, cuantitativos y mixtos (Johnson \& Onwuegbuzie, 2004). El pluralismo paradigmático ofrece la viabilidad de uso de varios paradigmas en estos métodos, pese a que exista una tendencia al posicionamiento pragmático de la mayoría de los investigadores (Teddlie \& Tashakkori, 2012; Lincoln et al., 2011).

Según Taylor y Bogdan (1984) se trata de un descubrimiento en progreso que responde a una pragmática adaptada a la necesidad de cada problema. La elección metodológica está supeditada al contexto en el que se produce la investigación, provocando un dinamismo y creatividad en los procesos de investigación gracias a los procedimientos críticos de valoración (Hernández et al., 2014).

A fin de recabar los datos en este estudio se ha elaborado un cuestionario ad hoc destinado a los docentes (https://bit.ly/formCV19) compuesto por 48 preguntas (formato abierto para la recopilación de datos identificativos y profesionales de los docentes, Likert para el identificar el grado de valoración sobre distintos aspectos relacionados con confinamiento educativo y un bloque final de preguntas abiertas con el objetivo de conocer de forma explícita la valoración del profesorado sobre las propuestas y causas que subyacen a las deficiencias señaladas) y que fueron validadas por una decena investigadores de las universidades Autónoma de Madrid, Granada y León. La elección de estas fuentes de validación viene avalada por la trayectoria investigadora en calidad educativa de dichos investigadores, con especial atención a los parámetros de calidad educativa, pedagogía digital así como didáctica y organización escolar. La difusión del mismo se realizó entre el 5 y el 27 de mayo de 2020, lanzándose a través de redes sociales (Twitter y Facebook) así como por grupos de WhatsApp, como se explica a continuación en la muestra de estudio.

El análisis de datos obtenidos se realizó a partir de análisis estadísticos inferenciales a partir de las necesidades identificadas a raíz de los primeros cálculos. Dado que el conjunto de preguntas era muy concreto, se consiguió realizar una comprensión en profundidad o grounded theory de las respuesta obtenidas sin el requerimiento de programas informáticos de análisis cualitativo (Glaser, 1998). 


\subsection{Muestra de estudio}

El objeto de estudio de la presente investigación responde a una muestra aleatoria, no intencional conformada por 3764 informantes, bajo la premisa de ejercer su labor docente en el territorio nacional durante el periodo del confinamiento del curso académico 20192020. El proceso participativo se ha llevado a cabo a través de la técnica bola de nieve, en el que se solicita la participación de un número determinado de informantes quienes, a su vez, transmiten el formulario a otros participantes que propician un número amplio de informantes que condicionan el objeto de estudio definitivo (Ruiz, 2008).

Del total de informantes, el 71,6 \% $(n=2674)$ corresponden a docentes de género femenino y el 28,4 ( $n=1061)$ son docentes de género masculino. Datos que mantienen la línea de estudios estadísticos previos (MEFP, 2019) que situaban la población docente femenina en un 72,1 \% durante el curso 2017-18. La distribución de edad se muestra también heterogénea. El grupo de edad mayoritario es el del grupo comprendido entre los 41-50 años, con un 34,4 \% ( $\mathrm{n}=1284)$, seguido por el grupo 31-40 años (28,9 \%, $\mathrm{n}=1079)$, 51-60 años $(24,3 \%, \mathrm{n}=907), 21-30$ años $(9,6 \%, \mathrm{n}=359)$ y el grupo de más de 60 años $(2,8 \%, \mathrm{n}=106)$.

Por lo que respecta a la titularidad de los centros educativos en los que ejercen como docentes, un 84,7 \% $(n=3163)$ corresponden a centros públicos, por un $11,6 \%(n=433)$ de centros concertados y un 3,7 $(n=139)$ pertenecientes a centros privados. Estos centros tienen un reparto heterogéneo por su procedencia, destacando centros de la Comuniad Valenciana (25,8 \%) seguidos por Castilla y León (13,1 \%), Madrid (12,8 \%), Aragón (7 \%) y Extremadura y Andalucía con un respectivo $6 \%$. El resto de comunidades arrojan valores inferiores al $5 \%$, estando representadas todas las autonomías del país.

La etapa educativa de los informantes también proporciona una tipología de los informantes. Las etapas de Educación Primaria (39 \%, n=1461), Educación Secundaria Obligatoria $(37,8 \%, n=1413)$ y Bachillerato $(24,1 \%, n=901)$ son las ofrecen mayor número de participaciones frente a Educación Infantil $(17,5 \%, \mathrm{n}=655)$, Formación Profesional $(10,1 \%, n=377)$, Universidad $(1,9 \%, n=72)$ u otras etapas educativas $(4,7 \%$, $\mathrm{n}=177)$. De su perfil docente, destacan los de formación generalista $(29,6 \%, \mathrm{n}=1105)$, del ámbito lingüístico (21,3\%, n=796), del ámbito científico-tecnológico (19,7\%, n=736), del ámbito físico-artístico-expresivo $(16,4 \%, \mathrm{n}=611)$, del ámbito humanístico y social $(14,1 \%$, $\mathrm{n}=525)$ u otros ámbitos $(13,4 \%, \mathrm{n}=499)$.

\section{Discusión de resultados}

\subsection{Resultados relativos a la experiencia previa del profesorado en la enseñanza a distancia}

El cuestionario comienza con una muestra del perfil profesional de los encuestados a partir de variables de su experiencia profesional y su bagaje formativo previo. Al ser requeridos sobre las modalidades profesionales que han experimentado antes del confinamiento, solo un $20 \%(\mathrm{n}=747)$ ha experimentado la formación a distancia o el 11,5 $\%(n=430)$ que lo ha hecho en el modelo mixto. La modalidad presencial es la predominante con un 89,6 \% ( $\mathrm{n}=3347)$ como se muestra en la figura 1 : 


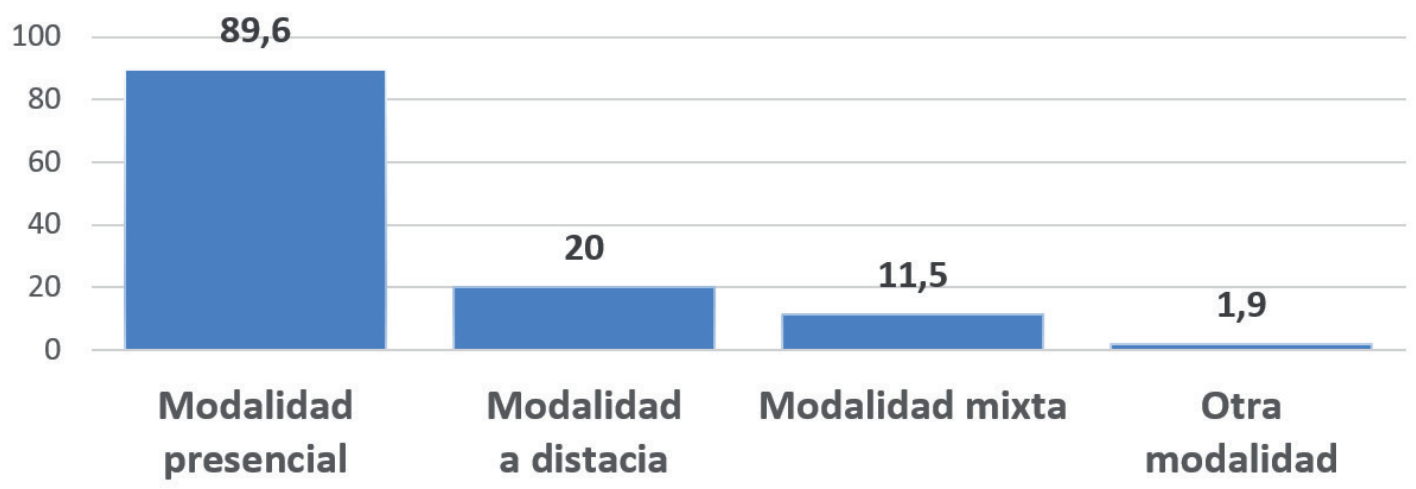

Figura 1. Modalidades docentes experimentadas por el profesorado antes del confinamiento por COVID-19

Datos que se vinculan a otro de los aspectos por los que se ha preguntado al profesorado: el nivel de experiencia en la formación a distancia (Figura 2). En el que hay resultados homogéneos entre la formación baja (42,6 \%, $\mathrm{n}=1593)$ o formación de nivel medio (32,5 \%, $\mathrm{n}=1213$ ) y escasos en los extremos del nivel nulo $(17,5 \%, \mathrm{n}=652)$ o alto $(7,4 \%, n=277)$. Datos que, asociados a la perspectiva de utilidad de la tecnología educativa por parte del profesorado, ofrecen una confrontación entre la perspectiva positiva hacia las TIC y la realidad en su implementación de los docentes, donde encuentran escollos para su puesta en práctica aludiendo a dificultades infraestructurales o formativas (Cabero-Almenara \& Martínez-Gimeno, 2019; Gallardo et al., 2020; Fernández \& Martínez, 2018).

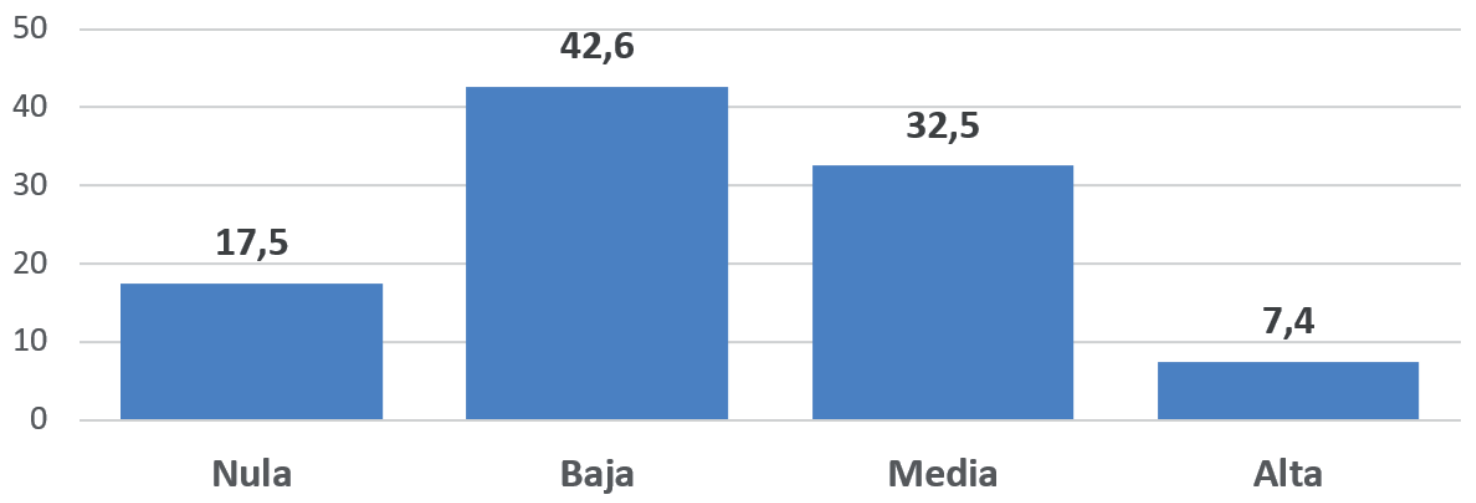

Figura 2. Porcentajes de docentes atendiendo a la experiencia formativa en formación a distancia.

La combinación de epistemología formativa en TIC y su pragmática en el aula se pone de relieve en la elección de las plataformas empleadas durante el confinamiento tanto para la comunicación con el alumnado como para el seguimiento académico. El uso heterogéneo de las herramientas digitales (Figura 3) no permite establecer patrones de conducta definidos ni diferenciados. Sobre esta cuestión, se indagó para conocer si la plataforma empleada había sido proporcionada por la Administración educativa o por el centro educativo, resultando un $64 \%$ de los docentes que trabajan con herramientas facilitadas por la administración. Resulta significativo que las plataformas teóricamente 
predominantes, compañías de ámbito y uso privado como Google Suite $(32,9 \%$, n=1230) o Microsoft Teams $(20,2 \%, n=756)$ no sean las mayoritarias, como tampoco las de acceso gratuito y proporcionadas por la administración educativa, como Moodle (23,5\%, $\mathrm{n}=879$ ). Los datos revelan que un importante número de docentes (el 59,3 \%, $\mathrm{n}=2213$ ) han optado por otros medios como correo el electrónico o las redes sociales (WhatsApp, Telegram).

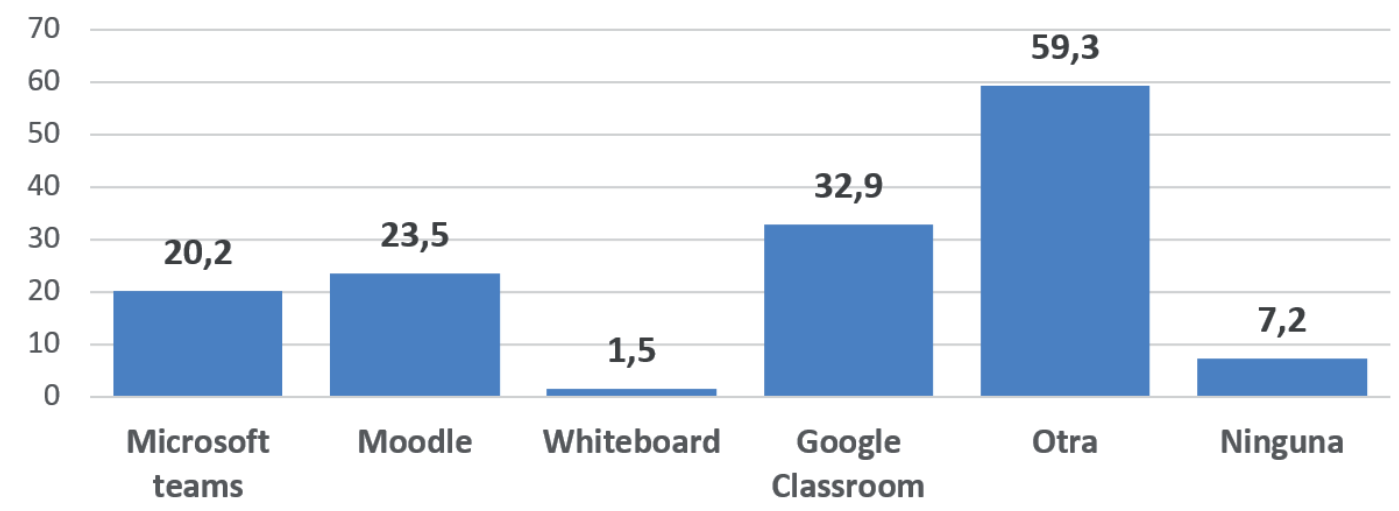

Figura 3. Porcentaje de uso de herramientas digitales para el desempeño de la práctica educativa por la muestra durante el confinamiento.

Un dato significativo es el de la proporción de informantes pertenecientes a la Administración pública ( $85 \%$ de los participantes) emplean plataformas privadas, propiciando un debate sobre la gestión de los datos de los alumnos, hecho sobre el que la Agencia Española de Protección de Datos (2018) establece una vigilancia más singular a través del control sobre los contratos que establecen las administraciones escolares con empresas que gestionan datos privados. Prueba de ello es la pregunta que se formuló sobre los otros medios de comunicación del profesorado con su alumnado (Figura 4) en la que el correo electrónico sigue predominando $(93,2 \%, \mathrm{n}=3479)$ frente a elecciones más homogéneas como las aplicaciones específicas de videoconferencia $(47,5 \%, \mathrm{n}=1774)$, las de mensajería instantánea como WhatsApp o Telegram $(46,3 \%, n=1728)$, el blog o la web del centro educativo ( $43 \%, \mathrm{n}=1604) \mathrm{u}$ otros medios $(19,6 \%, \mathrm{n}=733)$.

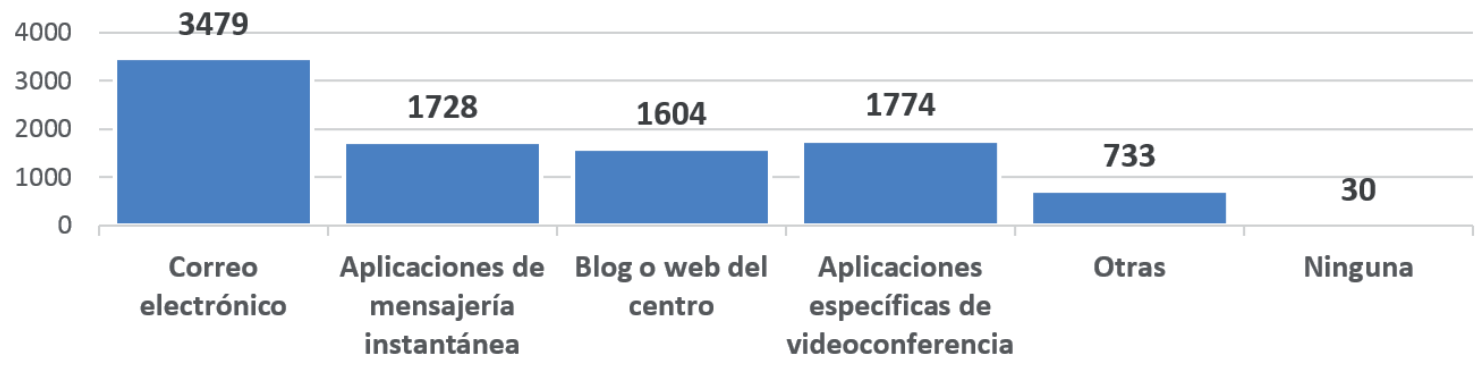

Figura 4. Usuarios totales de los distintos medios de comunicación educativos con el alumnado.

La gestión de las Administraciones educativas también ha sido una de las valoraciones por las que se ha preguntado al profesorado. Se ha empleado una escala numérica de 1 (muy mal) a 4 (muy bien). Datos que arrojan un desencuentro con la administración 
en los distintos ejes de actuación. El profesorado, al ser cuestionado por el grado de satisfacción ante la situación en las siguientes áreas:

- Directrices y normativas elaboradas por la Administración como respuesta de propio centro educativo.

- Respuesta del centro educativo en planes de formación digital del claustro docente.

- Materiales disponibles para la comunidad educativa durante el confinamiento.

- Armonización de las medidas adoptadas y propuestas a nivel nacional (Ministerio de Educación) y a nivel autonómico (Comunidades Autónomas).

Reflejándose los siguientes valores (Figura 5):

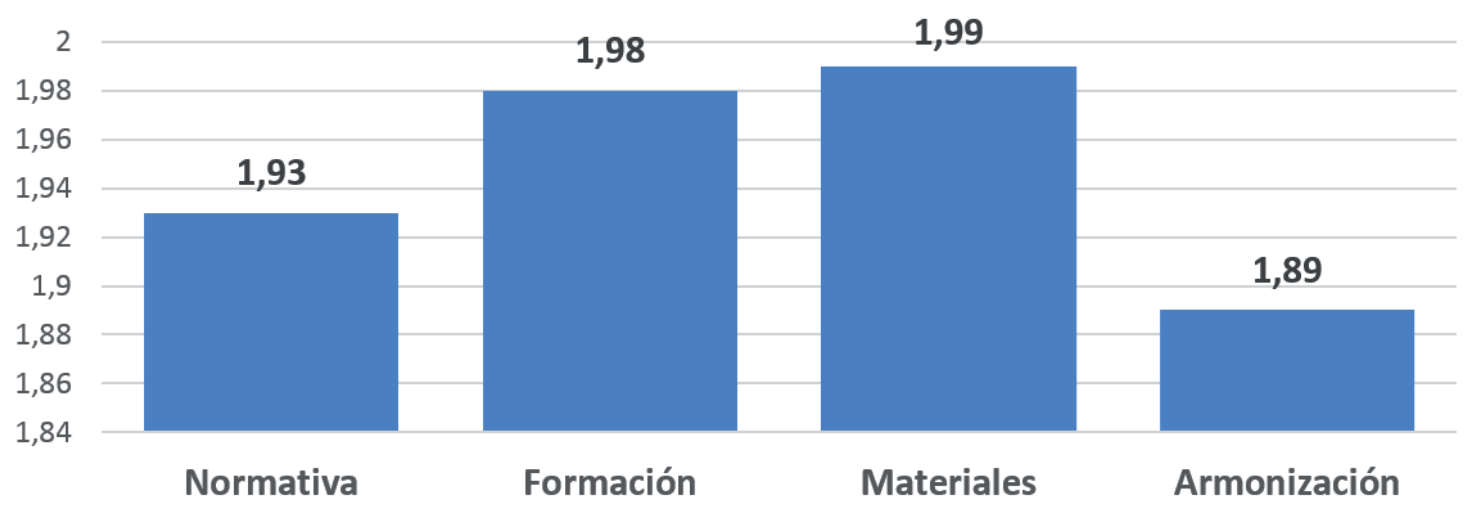

Figura 5. Valoración media de los docentes respecto a la actuación de las administraciones educativas.

Valores que corroboran una insatisfacción al no llegar en ninguna de las áreas a los dos puntos de valoración y que suscitan el interés del análisis de la frecuencia porcentual de la valoración del objeto de estudio sobre el papel desempeñado por las Administraciones educativas (Tabla 1):

Tabla 1.

Frecuencia porcentual de la valoración de la Administración educativa por parte de los docentes.

\begin{tabular}{lcccc}
\hline & Normativa & Formación & Materiales & Armonización \\
\hline Muy mal / Nulo & 29,7 & 28,9 & 289,1 & 33,5 \\
\hline Regular / Escaso & 49,5 & 46,8 & 46,0 & 46,2 \\
\hline Bien / Suficientes & 18,9 & 21,2 & 21,8 & 18,6 \\
\hline $\begin{array}{l}\text { Muy bien / } \\
\text { óptimos }\end{array}$ & 1,8 & 3,0 & 3,1 & 1,7 \\
\hline
\end{tabular}

La situación sobrevenida ha supuesto un sinfín de quejas por parte del profesorado al tener que transformar un sistema educativo de un día para otro. Más del $75 \%$ del objeto de estudio muestra su insatisfacción ante la respuesta de la Administración educativa en 
materia digital frente a menos del $25 \%$ que considera satisfactorios los materiales disponibles. Tan solo un $20 \%$ de los docentes considera adecuada la respuesta conjunta del Ministerio de Educación con las distintos gobiernos autonómicos en materia educativa.

Los datos ofrecen un desencuentro entre profesorado y la gestión de las Administraciones educativas. Esperando datos diferentes, se les ha preguntado la opinión sobre: la actuación de los centros educativos en los que han ejercicio su quehacer docente durante el confinamiento, la respuesta que han ofrecido el centro ante las necesidades sobrevenidas, los medios de los que dispone para ejercer la docencia, el modelo de educación virtual escogido por el centro educativo o el seguimiento llevado a cabo por la dirección del centro en coordinación con los equipos de orientación para el seguimiento del alumnado, han vuelto a dar valoraciones negativas (Figura 6). Se ha empleado un escala de 1 (muy mal) a 4 (muy bien), y solo se da un valor positivo, el que se refiere a la respuesta del centro, que llega al valor de 3 .

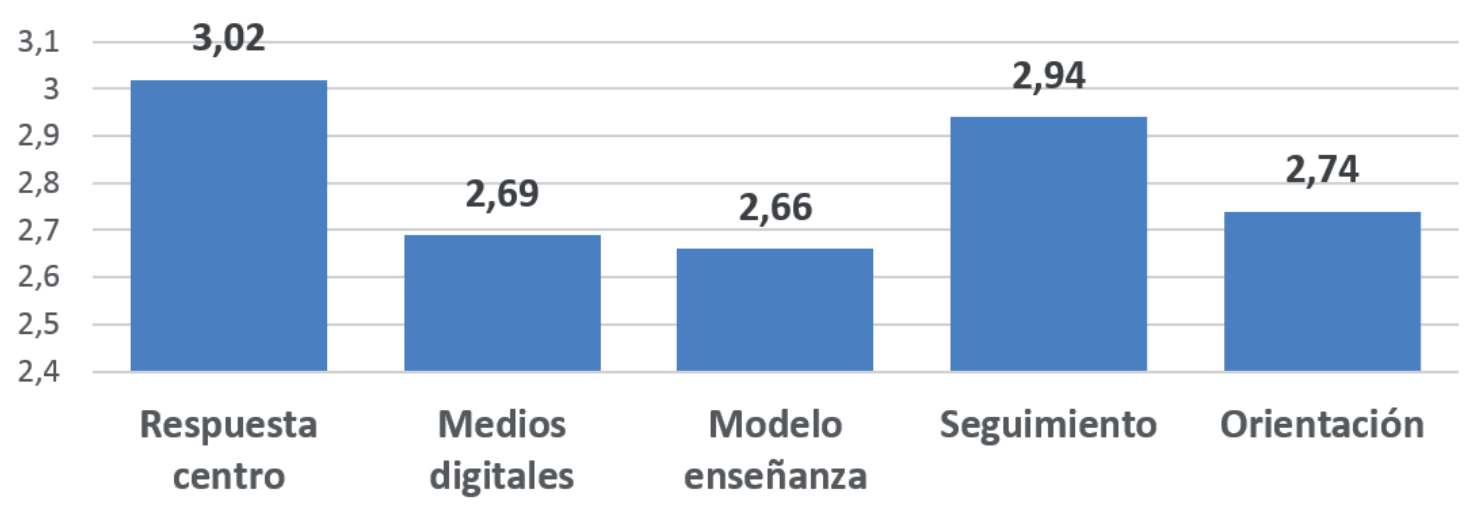

Figura 6. Valoración media de los docentes respecto al papel de sus centros educativos.

Datos que mantienen la correlación del 75,4 \% de los informantes, quienes consideran como buenas o muy buenas las respuestas a las necesidades educativas ofrecidas al confinamiento:

Tabla 2.

Frecuencia porcentual de la valoración de los centros educativos por parte de los docentes.

\begin{tabular}{lccccc}
\hline & $\begin{array}{c}\text { Respuesta del } \\
\text { centro }\end{array}$ & $\begin{array}{c}\text { Medios } \\
\text { digitales }\end{array}$ & $\begin{array}{c}\text { Modelo } \\
\text { enseñanza } \\
\text { virtual }\end{array}$ & Seguimiento & Orientación \\
\hline Muy mal / Nulo & 6,1 & 8,9 & 12,5 & 8,1 & 13,0 \\
\hline Regular / Escaso & 18,5 & 31,5 & 29,0 & 19,4 & 24,4 \\
\hline Bien / Suficientes & 42,4 & 41,0 & 38,4 & 42,4 & 38,6 \\
\hline Muy bien / óptimos & 33,0 & 18,6 & 20,2 & 30,1 & 24,0 \\
\hline
\end{tabular}

Frente al 18,6 \% que califica como óptimos los medios con los que cuenta su centro educativo, el 40,4 \% dictamina que son regulares o muy malos. Pese a que las Administraciones educativas facilitan a los centros educativos de medios digitales necesarios como plataformas, software y formación, un 41,5\% de los docentes califica como regular/escasa la coordinación de los claustros. En la faceta positiva, un 72,5 \% 
de los encuestados valora como bueno o muy bueno el seguimiento realizado desde los centros. Contrastan los valores que ofrece la visión de la coordinación del centro con equipo docente, un 58,5 \% lo calificaba como bueno o muy bueno, pero el seguimiento del centro educativo para con el profesorado, esta evaluación asciende hasta el 72,5\%. La intervención de los equipos de orientación se evalúa como regular o escasa por el 24,4 \%, mientras que un 62,6 \% la considera buena o muy buena la intervención con alumnos con necesidades. Por el contrario, el 37,4 \% establece que la labor de estos equipos ha sido mala o regular, datos que no ofrecen una interpretación positiva al tratarse de los responsables de la intervención y directrices para con este grupo de escolares.

\subsection{Valoración del profesorado respecto al apoyo de las familias}

Tras la evaluación de la Administración y los centros educativos, se sondeó al profesorado por el papel realizado de las familias, de quienes se valoraban los aspectos relacionados con el conocimiento de las familias del modelo de enseñanza virtual del centro, el apoyo de las familias a dicho modelo, el apoyo recibido por parte del profesorado, su grado de satisfacción en relación a la tutoría virtual y los medios digitales con los que contaba el alumnado para el seguimiento de la actividad escolar. En la figura 7, siguiendo la escala de casos previos, en valoración de 1 (muy mal) a 4 (muy bien), las variables superan el valor de 2, destacando el grado de satisfacción con las familias que ofrece un valor de 2,95.

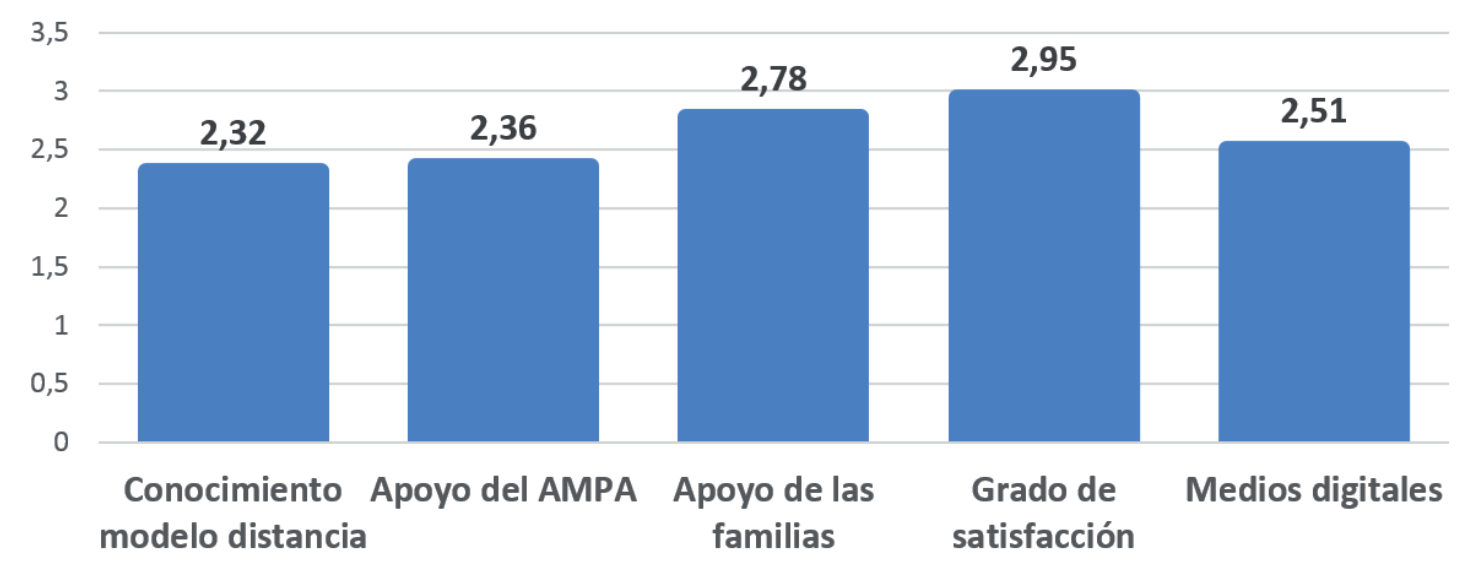

Figura 7. Valoración media de los docentes respecto al papel de las familias.

Estos datos muestran una muy buena percepción en cuanto al conocimiento que poseen las familias sobre las características del modelo de enseñanza digital del centro en el que sus hijos e hijas cursan estudios (Tabla 3). En cambio, es más evidente el porcentaje que valora como muy malo o regular $(70,2 \%)$ el conocimiento del que disponen las familias, bien por mediación del Consejo Escolar, bien por comunicación interna de los propios centros, de las características del modelo digital empleado por el centro. Únicamente un 8,3\% de los docentes valora muy positivamente el apoyo de las familias al modelo digital de enseñanza del centro: 
Tabla 3.

Frecuencia porcentual de la valoración de los docentes respecto al papel de las familias.

\begin{tabular}{lccccc}
\hline & $\begin{array}{c}\text { Conocimiento } \\
\text { del modelo }\end{array}$ & $\begin{array}{c}\text { Apoyo } \\
\text { AMPA }\end{array}$ & $\begin{array}{c}\text { Apoyo de las } \\
\text { familias }\end{array}$ & $\begin{array}{c}\text { Grado de } \\
\text { satisfacción }\end{array}$ & Medios \\
\hline $\begin{array}{l}\text { Muy mal / } \\
\text { Nulo }\end{array}$ & 14,8 & 18,3 & 6,3 & 2,9 & 7,8 \\
\hline $\begin{array}{l}\text { Regular / } \\
\text { Escaso }\end{array}$ & 45,4 & 39,7 & 28,1 & 19,8 & 41,4 \\
\hline $\begin{array}{l}\text { Bien / } \\
\text { Suficientes }\end{array}$ & 32,9 & 35,8 & 47,0 & 57,1 & 42,6 \\
\hline $\begin{array}{l}\text { Muy bien / } \\
\text { optimos }\end{array}$ & 6,9 & 8,3 & 18,7 & 20,4 & 8,2 \\
\hline
\end{tabular}

Queda patente la falta de respaldo que percibe el profesorado por parte del AMPA respecto al modelo digital de enseñanza. Hecho interpretable desde la clara dependencia del alumnado para con sus familias en los procesos de aprendizaje y que se acentúa en el modelo no presencial. Prueba de ello es que el $35 \%$ de los docentes valora como malo o regular el apoyo recibido en relación a la labor docente. Datos que mantienen la tendencia positiva marcada por el informe PISA 2018 que establecía que la participación e interacción padres era, bien por iniciativa de los progenitores (50 \%), bien por la del profesorado (68\%). Destaca positivamente que el $77 \%$ del profesorado entrevistado establece como buena o muy buena la satisfacción de las familias hacia la tutoría virtual desarrollada por los docentes. En cambio, el 23,5 \% considera que el grado de satisfacción de las familias en relación a la respuesta de su tutoría virtual es mala o regular. Casi la mitad del profesorado, un 49,2 \%, afirman que el $50 \%$ de su alumnado dispone de medios digitales (red de conexión wifi, ordenador, tableta o teléfono móvil) muy malos o escasos para su utilización en un modelo de educación a distancia.

Una última consideración en el análisis del profesorado es la que se deriva de los colectivos e instituciones educativas implicadas, así como una valoración de sí mismos (Figura 8). Para ello, se les solicitó que expresasen su grado de satisfacción con diversos aspectos relacionados con el profesorado. De forma más precisa, los cuatro ítems sobre los que debían indicar su particular punto de vista fueron:

- La tipología de formación del profesorado en el centro en el que desarrollan su carrera profesional en relación a la competencia digital para poder llevar a cabo la enseñanza a distancia.

- Las reuniones de coordinación con sus respectivos equipos docentes, de etapa o departamentales para afrontar la intervención digital.

- La retroalimentación pedagógica a través del conocimiento de experiencias docentes con otros colegas a través de redes sociales y/o plataformas de comunicación.

- La realización de tutorías personalizadas con el alumnado con necesidades. 


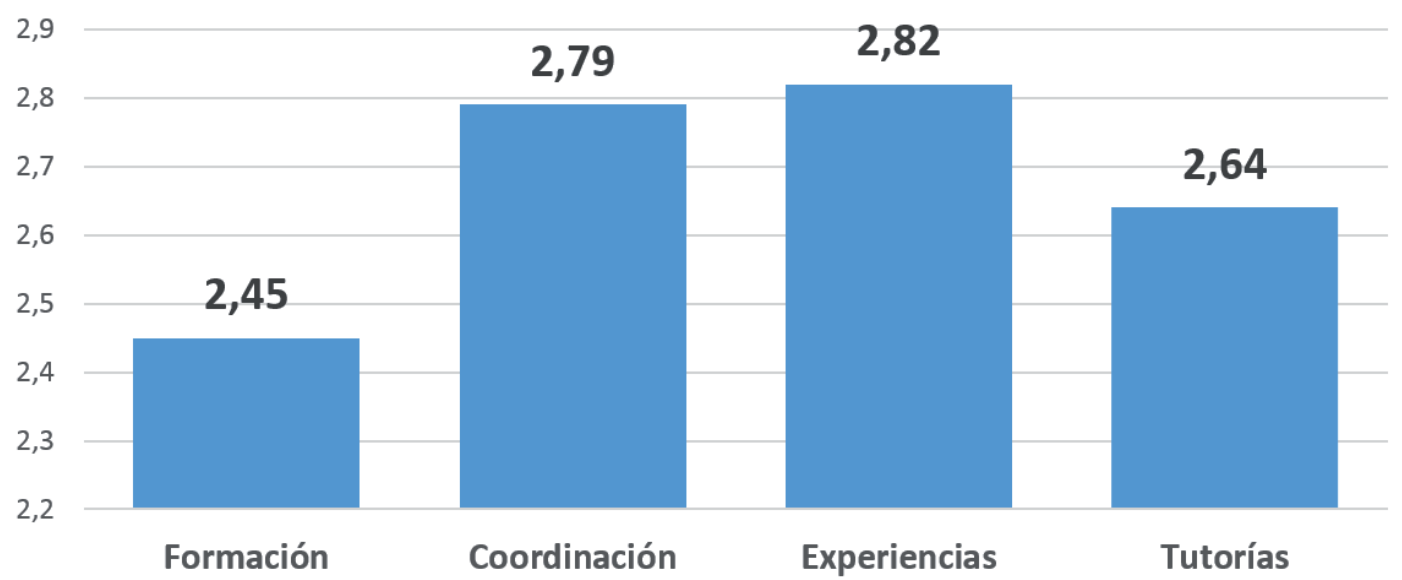

Figura 8. Valoración media de los docentes respecto al papel del profesorado.

Datos que se complementan con los reflejados en la tabla 4, donde se pueden interpretar unos resultados que mantienen una proporcionalidad. Entorno $8 \%$ del profesorado, considera que su formación / preparación en materia de competencia digital en su centro para abordar la modalidad virtual es muy mala o muy buena. Por el contrario, el $54,2 \%$ valora que dicha formación en su centro de trabajo -propia o de sus compañeros docentes- es muy mala o escasa. Partiendo de estos valores, se puede interpretar que la capacidad para desplegar un aprendizaje en un modelo digital a distancia presenta carencias significativas por parte del profesorado.

Tabla 4.

Frecuencia porcentual de la valoración de los docentes respecto al papel del profesorado.

\begin{tabular}{lcccc}
\hline & $\begin{array}{c}\text { Formación } \\
\text { profesorado }\end{array}$ & $\begin{array}{c}\text { Coordinación } \\
\text { docentes }\end{array}$ & $\begin{array}{c}\text { Intercambio de } \\
\text { experiencias }\end{array}$ & $\begin{array}{c}\text { Tutorías } \\
\text { alumnado }\end{array}$ \\
\hline Muy mal / Nulo & 8,9 & 10,5 & 9,6 & 12,3 \\
\hline Regular / Escaso & 45,3 & 23,8 & 24,0 & 29,3 \\
\hline Bien / Suficientes & 38,1 & 41,8 & 41,0 & 40,0 \\
\hline Muy bien / óptimos & 7,7 & 23,9 & 25,4 & 18,4 \\
\hline
\end{tabular}

Alrededor de dos tercios del profesorado entrevistado (65,7 \%) mantiene una buena o muy buena valoración de las reuniones de coordinación con su equipo de docentes, de ciclo o departamentales para la implementación de una metodología dentro del marco digital. Es llamativo que haya una valoración negativa de la formación del profesorado en cuanto a competencia digital pero, paradójicamente, la coordinación para llevar a cabo una implementación de dicha competencia digital se valora positivamente. Para el 66,4 $\%$ los intercambios de experiencias educativas a través de redes sociales o plataformas de comunicación con otros docentes resultan buenas o muy buenas. La interpretación de la pregunta puede haberse entendido como la valoración hacia otros colegas docentes que comparten sus experiencias para que puedan ser empleadas por otros docentes. En cambio, la pregunta tenía una intención opuesta, queriendo investigar qué grado de experiencias propias habían sido compartidas, así como recursos y materiales didácticos, por ellos mismos a través de dichos medios. Es por ello que contraste el punto de vista del 54,2 \% 
del profesorado que considera que la formación en competencia digital de su centro (tanto propia como de sus compañeros) para enfrentarse al modelo digital sea muy mala o regular, mientras que el $66,4 \%$ opine que ha compartido su experiencia en medios digitales con otros colegas docentes. Finalmente, para un 41,6 \% de los docentes, la realización de tutorías con alumnos con necesidades se considera que ha sido regular o muy mala.

Otra de las cuestiones que abordaba el cuestionario en relación a la labor docente era la de conocer el porcentaje aproximado de tiempo dedicado con su alumnado a tareas como la preparación de clases en el modelo virtual, la resolución de dudas, la corrección de tareas o la evaluación de los aprendizajes de su alumnado.

La figura 9 refleja las medias obtenidas para cada uno de los aspectos a analizar indicados previamente. Los porcentajes resultan prácticamente homogéneos entre los cuatro campos, destacando la tarea más valorada la de preparación de clases (39,4 \%) y la menos frecuente la de evaluación de aprendizajes (21,7\%).

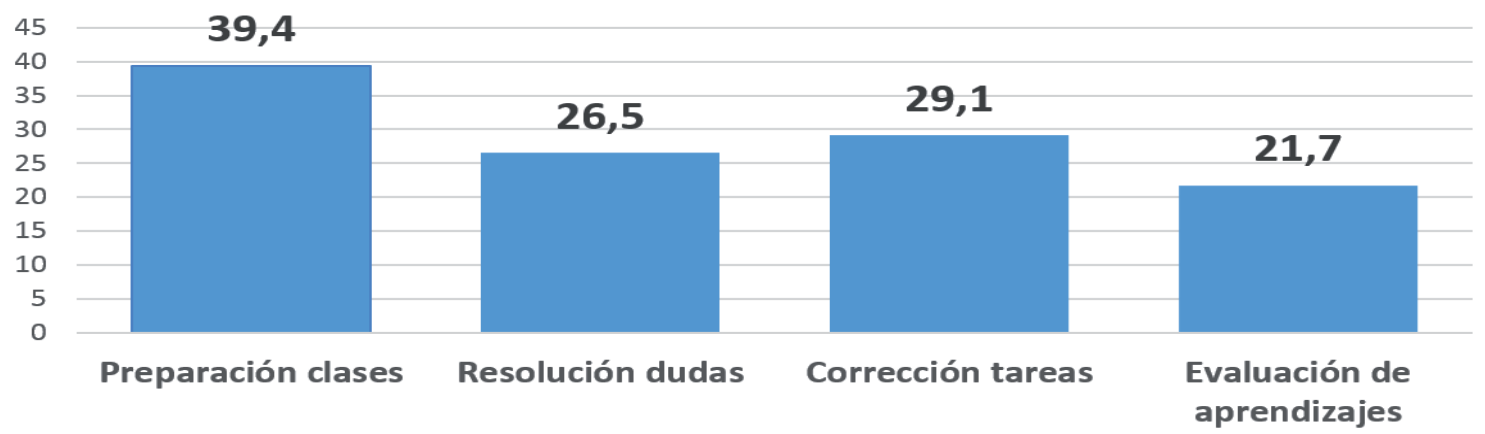

Figura 9. Porcentaje temporal destinado a tareas docentes.

En los datos que se muestran en la tabla 5 se concretan las respuestas ofrecidas para estos cuatro campos. Se impuso como condición para validar esta pregunta que la suma de las respuestas dadas para las cuatro áreas debía ser del $100 \%$.

Tabla 5 .

Frecuencia porcentual de tiempo dedicado a tareas docentes.

\begin{tabular}{ccccc}
\hline Porcentaje & $\begin{array}{c}\text { Preparación } \\
\text { de clases }\end{array}$ & $\begin{array}{c}\text { Resolución de } \\
\text { dudas }\end{array}$ & $\begin{array}{c}\text { Corrección } \\
\text { de tareas del } \\
\text { alumnado }\end{array}$ & $\begin{array}{c}\text { Evaluación } \\
\text { de } \\
\text { aprendizajes }\end{array}$ \\
\hline $\mathbf{0} \%$ & 0,9 & 2,6 & 5,9 & 8,4 \\
\hline $\mathbf{1 0} \%$ & 6,2 & 25,2 & 16,1 & 33,8 \\
\hline $\mathbf{2 0} \%$ & 19,5 & 31,3 & 28,2 & 35,5 \\
\hline $\mathbf{3 0} \%$ & 24,2 & 21,8 & 24,1 & 10,6 \\
\hline $\mathbf{4 0} \%$ & 17,0 & 7,8 & 10,6 & 1,9 \\
\hline $\mathbf{5 0} \%$ & 11,9 & 3,0 & 5,3 & 1,9 \\
\hline $\mathbf{6 0} \%$ & 7,4 & 2,1 & 2,8 & 1,5 \\
\hline $\mathbf{7 0} \%$ & 5,2 & 1,6 & 1,6 & 1,5 \\
\hline $\mathbf{8 0} \%$ & 3,4 & 1,6 & 1,8 & 1,4 \\
\hline $\mathbf{9 0} \%$ & 1,8 & 0,9 & 1,1 & 1,2 \\
\hline $\mathbf{1 0 0} \%$ & 2,4 & 2,0 & 2,5 & 2,1 \\
\hline
\end{tabular}


A partir de los cuatro ítems propuestos, la preparación de clases es la acción a la que más tiempo se dedica, siendo la respuesta mayoritaria para un 39,4\% del profesorado. Cabe recordar que el 40,2 \% del profesorado consultado opina que se halla entre una situación equidistante entre el modelo de enseñanza presencial con un fuerte protagonismo del libro de texto y el de los materiales elaborados por el propio profesorado para el trabajo por competencias de su alumnado. Este tiempo destinado para preparar clases, donde intuimos que se incluye la preparación o creación de recursos, es proporcional y necesario. Por otro lado, puede darse el caso que han enfrentarse a la preparación de recursos didácticos para su posterior envío por medios digitales, acción que comporta un esfuerzo notable si se le han de añadir las acciones de grabación, edición, producción y publicación de recursos audiovisuales (principalmente vídeos y video-tutoriales) que no se contemplaban como prioritarios en la enseñanza presencial en la propia aula.

\subsection{Valoración del profesorado respecto al apoyo de la Administración y los centros educativos.}

La siguiente pregunta es una de las más relevantes e importantes de toda la investigación. Tiene por objeto constatar si se produjo una brecha digital, y se aborda tras consultar el porcentaje aproximado de alumnado de su aula que no pudo seguir el modelo virtual durante el confinamiento por COVID-19. Las respuestas que se dan en la figura 10 son aclaradoras. Para el $45 \%$ del profesorado considera que más del $10 \%$ de su alumnado no siguieron la modalidad virtual o a distancia. Para un 22 \% de docentes entrevistados, ese porcentaje de alumnado con serias dificultades para seguir las clases virtuales se incrementa hasta un máximo del $20 \%$.

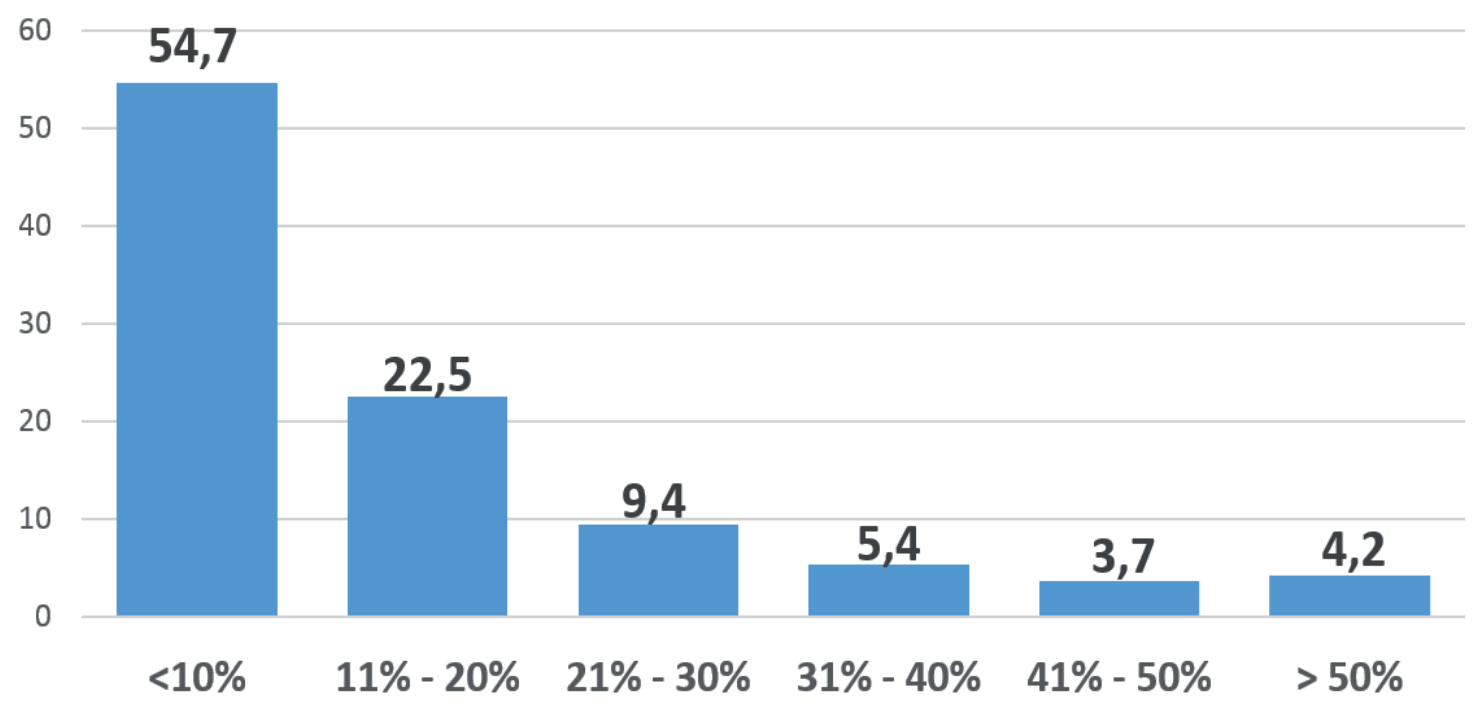

Figura 10. Porcentaje de alumnado, según el profesorado, que no ha podido seguir el modelo virtual durante el confinamiento.

Datos que se matizan tras consultar al profesorado sobre las principales causas que han propiciado las dificultades del alumnado para el seguimiento de las clases en su modalidad virtual. Dichas dificultades se focalizaron en siete causas principales que concentran los principales indicios para la imposibilidad de seguir el desarrollo académico normal: la baja formación en competencia digital del alumnado, la falta de medios 
tecnológicos, la falta de apoyo familiar, la falta o dificultad de acceso a una red de internet por parte del alumnado, la falta de coordinación entre docentes, el excesivo volumen de tareas, la falta de autorregulación de los estudiantes. Como se puede atestiguar en la figura 11, donde se comprueba en una escala de 1 (nada) a 4 (mucho) aquellos aspectos que han dificultado el seguimiento, destaca con un 1,72 de media una falta de coordinación entre el equipo docente, mientras que el valor más alto, con un 2,67 es aquel que alude a la falta de medios tecnológicos.

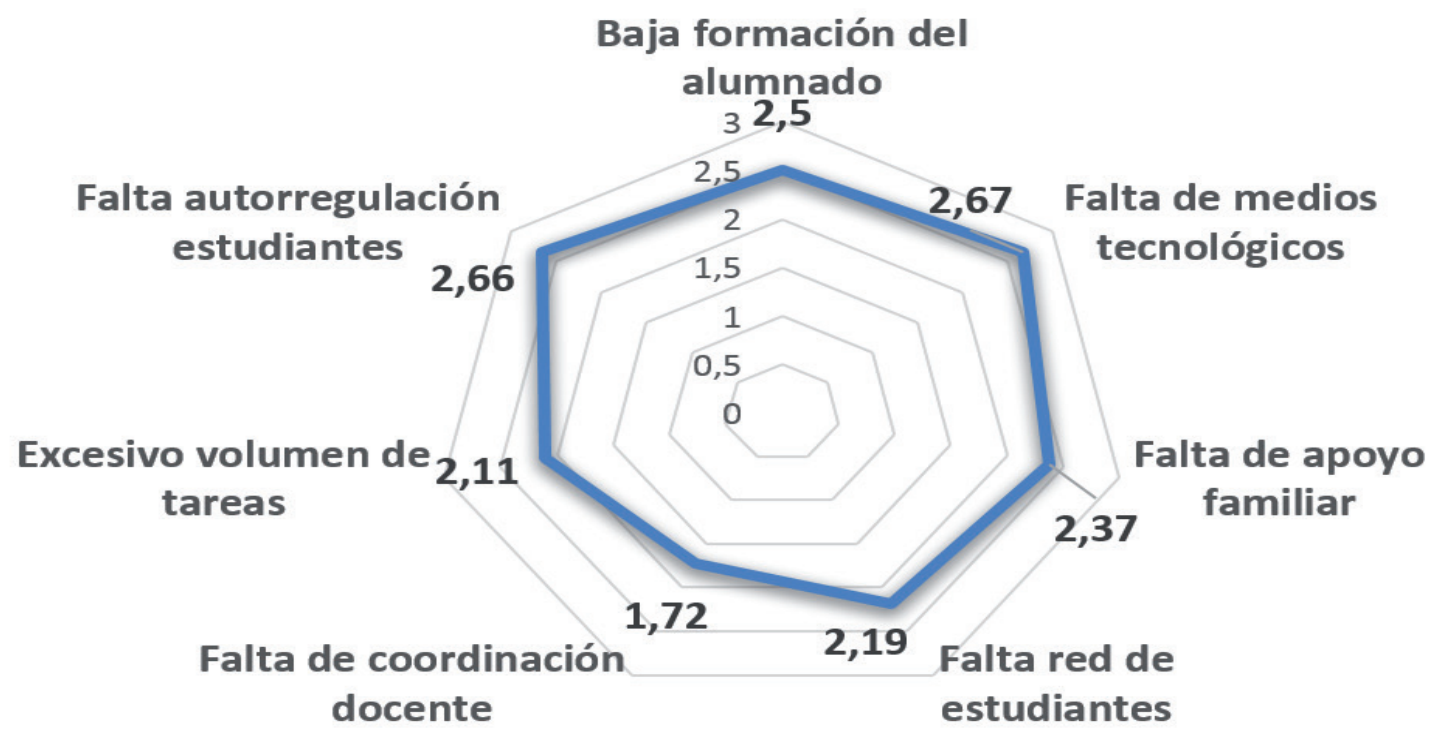

Figura 11. Valoración del profesorado respecto a las causas que han incentivado las dificultades para que el alumno haya seguido el ritmo de las clases virtuales.

Apreciaciones que se concretan en la tabla 6 en relación a la frecuencia con la que el profesorado identifica dichas dificultades de su alumnado para el seguimiento del modelo virtual de aprendizaje:

Tabla 6.

Frecuencia porcentual de la valoración de los docentes respecto a las dificultades del alumnado para el seguimiento del modelo virtual de aprendizaje.

\begin{tabular}{lccccccc}
\hline & $\begin{array}{c}\text { Falta } \\
\text { formación } \\
\text { profesorado }\end{array}$ & $\begin{array}{c}\text { Falta de } \\
\text { medios } \\
\text { tecnológicos }\end{array}$ & $\begin{array}{c}\text { Falta de } \\
\text { apoyo } \\
\text { familiar }\end{array}$ & $\begin{array}{c}\text { Falta de } \\
\text { red de } \\
\text { alumnado }\end{array}$ & $\begin{array}{c}\text { Falta } \\
\text { coordinación } \\
\text { docente }\end{array}$ & $\begin{array}{c}\text { Excesivo } \\
\text { volumen } \\
\text { tareas }\end{array}$ & $\begin{array}{c}\text { Falta } \\
\text { autore- } \\
\text { gulación } \\
\text { alumnado }\end{array}$ \\
\hline Nada & 14,3 & 9,6 & 14,2 & 21,4 & 47,6 & 26,8 & 12,3 \\
\hline Poco & 37,3 & 36,7 & 45,9 & 46,5 & 36,9 & 42,9 & 28,5 \\
\hline Bastante & 33,1 & 31,2 & 28,8 & 24,1 & 11,8 & 23,4 & 39,6 \\
\hline Mucho & 15,3 & 22,5 & 11,1 & 8,0 & 3,7 & 7,0 & 19,5 \\
\hline
\end{tabular}

El 53,7 \% del profesorado (correspondiente al ítem Falta de medios tecnológicos de la tabla 6) otorga un valor significativo a la ausencia de medios tecnológicos como principal motivo que ha impedido el seguimiento de las clases virtuales por parte de su alumnado. El 6o,1 \% identifica que la falta de apoyo del entorno familiar como poco o 
nada como principal motivo para el poder seguir las clases presenciales. Por su parte, el 39,9 \% del profesorado identifica que la falta de apoyo por parte de la familia ha influenciado bastante o mucho en dichas carencias. En relación al intercambio de experiencias entre estudiantes, un amplio 67,9\% valora que la ausencia de esa red de intercambio de experiencias entre alumnado ha tenido poca incidencia (poco o nada) en las dificultades sugeridas. Con un 84 \% de valoración del profesorado, se considera que ha tenido nada o poco la falta de coordinación del claustro docente. Porcentaje similar es el registrado, un 70 \%, como valoración (poco o nada) hacia la excesiva tarea por parte de los docentes como motivo principal para el no seguimiento del modelo virtual. Respecto a la perspectiva del alumnado, se registra un $60 \%$ por parte del profesado que identifica como bastante o mucha la ausencia de autorregulación del alumnado como causa que imposibilita el seguimiento de las clases virtuales.

Estas consideraciones conducen a valorar cuál es el grado de aceptación o discrepancia respecto a distintos aspectos de la formación y competencia digital docente (CDD). Estas consideraciones tenían por objeto el analizar el tipo de formación recibida y la propia percepción del profesorado atendiendo a la formación:

- Recibida por medio de formación regulada por la Administración.

- Recibida por medios autodidactas.

- Recibida en el centro de trabajo como parte del desarrollo curricular.

- Recibida en metodologías, evaluación e implementación en entornos virtuales.

- Permite valorarse como satisfactoria para un entorno virtual de aprendizaje.

A tenor de los datos mostrados en la figura 12, con valores variables entre 1 (nada de acuerdo) y 4 (totalmente de acuerdo), la variable con datos superiores es la que tiene en la formación autodidacta como principal fuente de formación con un 3,34. En el lado opuesto se encuentra la formación en metodologías, evaluación e implementación en tornos virtuales, registrando un valor medio de 2,26.

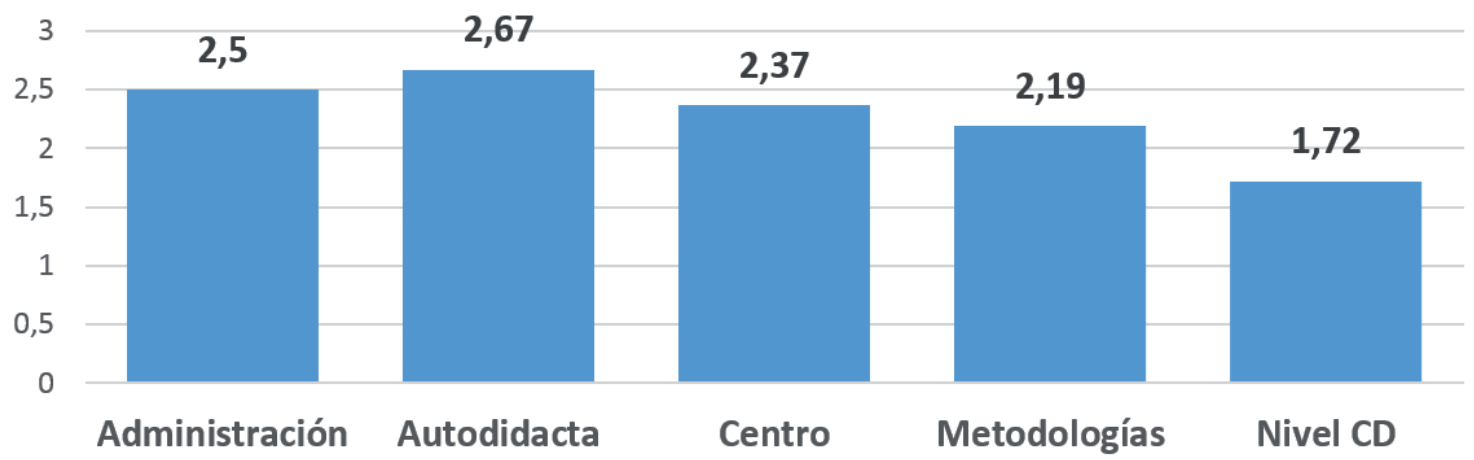

Figura 12. Valoración del profesorado respecto a su formación y competencia digital.

Valoraciones que se ven refrendadas por la tendencia que se manifiesta en la tabla 7 , donde el origen autodidacta de la formación alcanza el $90 \%$, mientras que la formación cuyo origen se sitúa en la Administración (46,5 \%) y el propio centro de trabajo $(45,4)$ sitúan a dicha formación por debajo de la mitad de la principal fuente formativa. 
Tabla 7.

Frecuencia porcentual de la valoración de los docentes respecto a su formación y CDD.

\begin{tabular}{lccccc}
\hline & $\begin{array}{c}\text { Formación } \\
\text { Administración }\end{array}$ & $\begin{array}{c}\text { Formación } \\
\text { autodidacta }\end{array}$ & $\begin{array}{c}\text { Formación } \\
\text { en centro }\end{array}$ & $\begin{array}{c}\text { Formación } \\
\text { metodológica }\end{array}$ & Nivel CDD \\
\hline Nada de acuerdo & 23,7 & 2,3 & 24,8 & 26,4 & 5,8 \\
\hline En desacuerdo & 29,9 & 7,2 & 29,8 & 33,7 & 27,3 \\
\hline De acuerdo & 32,7 & 45,2 & 32,6 & 27,9 & 45,3 \\
\hline $\begin{array}{l}\text { Totalmente de } \\
\text { acuerdo }\end{array}$ & 13,8 & 45,4 & 12,8 & 12,1 & 21,6 \\
\hline
\end{tabular}

La valoración sobre la CDD por parte del propio profesorado muestra que un 66,9 \% valora que goza de una buena CDD para abordar la formación virtual por un mínimo 5,8 \% de docentes que se sitúa en el polo opuesto, valorándose no estar en posesión de una adecuada CDD. Tan solo el 40 \% valora estar de acuerdo o totalmente de acuerdo con haber recibido formación en metodologías, evaluación y su implementación en plataformas virtuales de aprendizaje.

\section{Conclusiones}

La crisis sanitaria originada por la COVID-19 ha puesto de manifiesto una profunda crisis en el aprendizaje (Rodicio-García et al., 2020) y en un modelo educativo de nueva creación (Cabero-Almenara \& Llorente-Cejudo, 2020). La brecha digital de base socioeconómica no solo afecta a los centros educativos, sino que manifiesta un impacto heterogéneo de desigualdad en el acceso a la información y formación (Moreno et al., 2020; Trujillo et al., 2020). A partir de los datos obtenidos se puede aseverar que hasta un $30 \%$ del alumnado ha tenido problemas para el seguimiento de la docencia a distancia por ausencia de medios tecnológicos. El $65 \%$ del profesorado manifiesta con buen grado de satisfacción el apoyo dispensado por parte de las familias, verdaderos protagonistas en el liderazgo del nuevo modelo de aprendizaje domiciliario. Asimismo, el grado de satisfacción para con su propio tutorizaje virtual es, para un 75 \% del profesorado, como bueno o muy bueno. Es por ello que para un grupo de alumnado comprendido entre el $25 \%$ y el $35 \%$ las múltiples dificultades sobrevenidas han dificultado seriamente el seguimiento de las clases desde sus domicilios.

El confinamiento, como estado excepcional de la sociedad y de la Educación, ha conducido a todo el sistema educativo (Administración educativa, centros escolares, familias, alumnado, metodología y tecnología educativa) a una situación límite sin precedente en nuestro país. El 80 \% del profesorado consultado califica como regulares o nulas las directrices marcadas por la Administración, al tiempo que menos de un cuarto de los encuestados valora como suficientes, buenos o muy buenos los materiales disponibles desde las propias Administraciones. Estas entidades oficiales también quedan en un segundo plano por parte del profesorado al reconocer estos (36\%) que trabajan con plataformas educativas en sus centros que no han sido proporcionadas por la Administración, al tiempo que un 13,8 \% reconoce haber recibido formación procedente de organismos oficiales de la administración, siendo la autoformación el mecanismo de 
adquisición de la CDD más empleado por el profesorado, con un 90,6 \%, algo que está en sintonía con la evolución de la formación en tecnologías digitales del profesorado en estos últimos años (Álvarez-Herrero, 2020). La digitalización de los centros educativos ha pasado de ser protagonizada por organismos oficiales a ser un proceso inmerso dentro de una creciente tendencia de mercantilización (Teräs et al., 2020; Cuban, 2020) que sitúa este crecimiento tecnológico fuera del alcance de la Administración. Los centros gozan de una autonomía que, buscando minimizar las brechas existentes, crea un desarrollo desigual entre centros educativos próximos (Cabero-Almenara \& Llorente-Cejudo, 2020; Gallardo et al., 2020).

El profesorado tiene una percepción positiva de los aspectos derivados de su intervención en el contexto de confinamiento educativo. Opiniones que contrastan con las que se vierten sobre las Administraciones educativas (nacionales y autonómicas), así como hacia su centro de trabajo. El trabajo de cooperación entre equipos docentes y equipos directivos llega hasta el $60 \%$ de valoración positiva por parte de los primeros. Los resultados también arrojan resultados satisfactorios en la interacción constructiva entre docentes y familias para el seguimiento de los procesos de enseñanza y aprendizaje a distancia. Un $77,5 \%$ de los docentes considera muy positivo el seguimiento y respuesta de las familias, datos que se relacionan con el porcentaje de alumnado con dificultades de acceso y seguimiento durante el confinamiento.

Para los docentes, el acceso a internet ha sido una de las mayores dificultades junto con las carencias formativas y de adaptación al vasto y extenso currículum que no ha facilitado la puesta en marcha de un modelo pedagógico adaptado a las competencias y circunstancias. Los resultados corroboran que aquellos docentes que disponían de un plan de formación continuado y basado en un aprendizaje competencial se han adaptado de una forma menos traumática que aquellos que han tenido que improvisar y adaptar el modelo presencial a un marco virtual, confirmando estudios previos en la apuesta por el aprendizaje competencial mediado por tecnología (Sangrà et al., 2019; Soto et al., 2020; Romeu-Fontanillas et al., 2020; Moya \& Hernández-Ortega, 2020; Pinto et al., 2017). Idea que guarda relación directa con la formación recibida por los centros, puesto que el 54,2 \% del profesorado confirma que la formación en CDD (propia o de sus colegas docentes) es nula o escasa y tan solo el 12,8 \% confirma haber recibido formación específica en CDD por parte de su centro para el desarrollo curricular. Cuestión que refleja la necesidad de establecer itinerarios formativos que abastezcan no solo de los conocimientos instrumentales necesarios para la adquisición de la CDD (ÁlvarezHerrero \& Gisbert, 2015; Pozo-Sánchez et al., 2020a; Pozo-Sánchez et al, 2020b), sino de incentivar el desarrollo curricular de los centros que muestran una necesidad tangible por la actualización metodológica (Cabero-Almenara \& Palacios Rodríguez, 2020; Aznar Sala, 2020; Azorín, 2020).

\section{Referencias}

Álvarez-Herrero, J. F. (2020). Evolución de la percepción del docente de secundaria español sobre la formación en TIC. Edutec. Revista Electrónica De Tecnología Educativa, 71, 1-15. https://doi.org/10.21556/edutec.2020.71.1567

Álvarez-Herrero, J. F. \& Gisbert, M. (2015). Grado de alfabetización informacional del profesorado de Secundaria en España: Creencias y autopercepciones [Information Literacy Grade of Secondary School Teachers in Spain - Beliefs and SelfPerceptions]. Comunicar, 45, 187-194. https://doi.org/10.3916/C45-2015-20 
Area-Moreira, M., Bethencourt-Aguilar, A. \& Martín-Gómez, S. (2020). De la enseñanza semipresencial a la enseñanza online en tiempos de Covid19. Visiones del alumnado. Campus Virtuales, 9(2), 35-50. http://bit.ly/3bqguhi

Aznar Sala, F. J. (2020). La Educación Secundaria en España en Medio de la Crisis del COVID-19. International Journal of Sociology of Education, Special Issue: COVID-19 Crisis and Socioeducative Inequalities and Strategies to Overcome them, 53-78. http://doi.org/10.17583/rise.2020.5749

Azorín, C. (2020). Beyond COVID-19 supernova. Is another education coming?. Journal of Professional Capital and Community, 5(3-4), 381-39o. https://doi.org/10.1108/ JPCC-05-2020-0019

Burgess, S. \& Sievertsen, H. H. (1 de julio de 2020). Schools, skills, and learning: The impact of COVID-19 on education. VoxEu CEPR. https://voxeu.org/article/ impact-covid-19-education

Cabero-Almenara, J. \& Martínez Gimeno, A. (2019). Las tecnologías de la información y comunicación y la formación inicial de los docentes: modelos y competencias digitales. Profesorado: Revista de Currículum y Formación de Profesorado, 23(3), 247-268. https://doi.org/10.30827/profesorado.v23i3.9421

Cabero-Almenara, J. \& Palacios Rodríguez, A. d. P. (2020). Metareflexión sobre la competencia digital docente: análisis de marcos competenciales. Revista Panorámica, 32, 32-48. https://hdl.handle.net/11441/101703

Cabero-Almenara, J. \& Llorente-Cejudo, C. (2020). Covid-19: transformación radical de la digitalización en las instituciones universitarias. Campus Virtuales, 9(2), 25-34 http://bit.ly/3sh1AQe

Cuban, L. (2004). The blackboard and the bottomline. Why schools can't be businesses. Harvard University press.

Fernández-Regueira, U., Gewerc, A. \& Llamas-Nistal, M. (2020). El profesorado universitario de Galicia y la enseñanza remota de emergencia: condiciones y contradicciones. Campus Virtuales, 9(2), 9-24. http://bit.ly/3i3mJsA

Fernández, E. \& Martínez, J. (2018). Ecologías de Aprendizaje: Educación Expandida en Contextos Múltiples. Morata.

Gallardo, I. M., De Castro, A. \& Saiz, H. (2020). Interacción y uso de tecnologías en los procesos de enseñanza y aprendizaje. Educatio Siglo XXI, 38(1), 119-138. https:// doi.org/10.6018/educatio.413441

García-Peñalvo, F. J. \& Corell, A. (2020). La CoVId-19: ¿Enzima de la transformación digital de la docencia o reflejo de una crisis metodológica y competencial en la educación superior?. Campus Virtuales, 9(2), 83-98 http://bit.ly/3nzHbTc

Glaser, B. (1998). Doing Grounded Theory. Issues and Discussions. The Sociology Press. 
Gromova, N. S. (2020). Pedagogical risks as consequences of the Coronavirus COVID-19 spread. In Proceedings of the Research Technologies of Pandemic Coronavirus Impact(RTCOV 2O2O), pp. 350-355. https://doi.org/10.2991/assehr.k.201105.063

Hernández-Sampieri, R., Fernández, C. \& Baptista, P. (2014) Metodología de la investigación. McGraw Hill.

La Velle, L. (2020). The Challenges for Teacher Education in the 21st Century: Urgency, Complexity and Timeliness. Journal of Education for Teaching, 4(1), 1-3. https:// doi.org/10.1080/02607476.2019.1708621

Lincoln, Y. S., Lynham, S. A. \& Guba, E. G. (2011). Paradigmatic controversies, contradictions, and emerging confluences, revisited. The Sage handbook of qualitative research, 4, 97-128

Ministerio de Educación y Formación Profesional (2019). Datos y cifras. Curso escolar 2019/2020. MEFP.

Moreno, J. M., Bolivar, A., Clavijo, M., Cortés, J., Gómez, J. A., Hernández-Ortega, J., Fuentes, F., Fernández, J., Hortigüela, D., López, M., Pérez, Á., Luengo, F. \& Manso, J. (2020). Informe de investigación COVID19: Voces de docentes y familias, Proyecto Atlántida. http://hdl.handle.net/10486/691408

Moya, J. \& Hernández-Ortega, J. (2020). Una metamorfosis educativa para alcanzar un desarrollo humano sostenible. Profesorado. Revista de Currículum y Formación de Profesorado, 24(3), 149-173. http://doi.org/10.30827/profesorado.v24i3.15971

ONU (2019). 17 Goals to Transform Our World. Sustainable Development Goals, https:// www.un.org/sustainabledevelopment/

Pinto, A.R., Cortés, O., \& Alfaro, C. (2017). Hacia la transformación de la práctica docente: modelo espiral de competencias TICTACTEP. Píxel-Bit, 51, 37-51. https://doi. org/10.12795/pixelbit.2017.i51.03

Pozo Sánchez, S., López Belmonte, J., Fernández Cruz, M. \& López Núñez, J. A. (2020a) Análisis correlacional de los factores incidentes en el nivel de competencia digital del profesorado. Revista Electrónica Interuniversitaria De Formación Del Profesorado, 23(1). https://doi.org/10.6018/reifop.396741

Pozo-Sánchez, S., López-Belmonte, J., Rodríguez-García, A. M. \& López-Núñez, J. A. (2020b). Teachers' digital competence in using and analytically managing information in flipped learning, Culture and Education, 32(2), https://doi.org/10 $.1080 / 11356405.2020 .1741876$

Rodicio-García, M. L., Ríos-de-Deus, M. P., Mosquera-González, M. J. \& Penado Abilleira, M. (2020). La Brecha Digital en Estudiantes Españoles ante la Crisis de la Covid-19. Revista Internacional De Educación Para La Justicia Social, 9(3), 103-125. https://doi.org/10.15366/riejs2020.9.3.006

Romeu-Fontanillas, T., Guitert-Catasús, M., Raffaghelli, J. \& Sangrà, A. (2020). Ecologías de aprendizaje para usar las TIC inspirándose en docentes referentes. Comunicar, 62, 31-42. https://doi.org/10.3916/C62-2020-03 
Ruiz, A. (2008) La muestra: algunos elementos para su confección. Revista d'Innovació i Recerca en Educació, 1, 75-88.

Sangrà, A., Raffaghelli, J. \& Guitert, M. (2019). Learning ecologies through a lens: Ontological, methodological and applicative issues. A systematic review of the literature. British Journal of Educational Technology, 5O(4), 1619-1638. https:// doi.org/10.1111/bjet.12795

Soto, R., Sanz, M. \& Boumadan, M. (2020). La realidad de la brecha de conectividad en el ámbito educativo español: análisis de la situación actual, Innoeduca. International Journal of Technology and Educational Innovation, 6(1), 56-65. http://dx.doi. org/10.24310/innoeduca.2020.v6i1.7741

Taylor, S. J. \& Bogdan, R. (1984). Introducción a los métodos cualitativos de investigación. Paidós.

Teddlie, C. \& Tashakkori, A. (2003). Major issues and controversies in the use of mixed methods in the social and behavioral sciences. In A. Tashakkori and C. Teddlie (Eds.), Handbook of mixed methods in social and behavioral research, ThousandOaks Sage, 3-50.

Tejedor, S., Cervi, L., Pérez-Escoda, A. \& Jumbo, F. T. (2020). Digital Literacy and Higher Education during COVID-19 Lockdown: Spain, Italy, and Ecuador. Publications, 8(4), 48. https://doi.org/10.3390/publications8040048

Teräs, M., Suoranta, J., Teräs, H. \& Curcher, M. (2020). Post-Covid-19 Education and Education Technology 'Solutionism': a Seller's Market. Postdigital Science and Education, 2, 863-878. https://doi.org/10.1007/s42438-020-00164-x

Trujillo, F., Fernández, M., Montes, M., Segura, A., Alaminos, F. J. \& Postigo, A. Y. (2020). Panorama de la educación en España tras la pandemia de COVID-19: la opinión de la comunidad educativa. Fad. http://doi.org/10.5281/zenodo-3878844

UNESCO (2020). Adverse consequences of school closures. UNESCO. https://en.unesco. org/covid19/educationresponse/consequences 